\title{
Enhanced Flotation Separation of Cassiterite from Calcite Using Metal-Inorganic Complex Depressant
}

\author{
Guanfei Zhao ${ }^{1}$ and Dongmei $\mathrm{Zhu}{ }^{2, *}$ \\ 1 School of Minerals Processing and Bioengineering, Central South University, Changsha 410083, China; \\ fly.guan@163.com \\ 2 School of Resource and Environmental Engineering, Jiangxi University of Science and Technology, \\ Ganzhou 341000, China \\ * Correspondence: 9120190063@jxust.edu.cn
}

check for updates

Citation: Zhao, G.; Zhu, D. Enhanced Flotation Separation of Cassiterite from Calcite Using Metal-Inorganic Complex Depressant. Minerals 2021, 11, 880. https:// doi.org/10.3390/min11080880

Academic Editors: Saeed Chehreh Chelgani and Reza Dehghan

Received: 21 July 2021

Accepted: 11 August 2021

Published: 14 August 2021

Publisher's Note: MDPI stays neutral with regard to jurisdictional claims in published maps and institutional affiliations.

Copyright: (C) 2021 by the authors. Licensee MDPI, Basel, Switzerland. This article is an open access article distributed under the terms and conditions of the Creative Commons Attribution (CC BY) license (https:// creativecommons.org/licenses/by/ $4.0 /)$.

\begin{abstract}
At present, the research on flotation separation of cassiterite and gangue minerals is mainly focused on the development of new collectors or depressants, while the research on combined depressants is rare. In this study, the flotation separation of cassiterite and the typical gangue mineral, calcite, was investigated using the metal-inorganic complex depressant AlSS, composed of aluminum sulfate $\left(\mathrm{Al}_{2}\left(\mathrm{SO}_{4}\right)_{3}\right)$ and water glass $\left(\mathrm{Na}_{2} \mathrm{SiO}_{3} \cdot 4 \mathrm{H}_{2} \mathrm{O}\right)$. The flotation results indicated that, with the assistance of $\mathrm{Al}^{3+}$, the inhibition effect of SS (water glass) on calcite is significantly enhanced, while the inhibition effect on cassiterite is almost unchanged. The zeta potential and adsorption measurements proved that the formation of the negatively charged colloidal particles composed of $\mathrm{Al}_{\mathrm{m}}(\mathrm{OH})_{\mathrm{n}}{ }^{3 \mathrm{~m}-\mathrm{n}}$ and $\mathrm{SiO}_{\mathrm{m}}(\mathrm{OH})_{\mathrm{n}}{ }^{4-2 \mathrm{~m}-\mathrm{n}}$ tended to adsorb on the positively charged calcite surface, inhibiting the adsorption of sodium oleate ( $\mathrm{NaOL}$ ), while the adsorption of the colloidal particles on the negatively charged cassiterite surface is relatively less. The contact angle measurements indicate that the contact angle of cassiterite in the NaOL + AlSS solution is obviously larger than that of calcite, which indicates that cassiterite has better floatability in this system. The X-ray photoelectron spectroscopy (XPS) analysis confirms the Al and Si species are adsorbed on the surface of calcite, but not on the cassiterite. In addition, the adsorption of AlSS on cassiterite and calcite changes the chemical environment on the calcite surface, indicating that the adsorption of AISS on the mineral surface is more inclined to be through a chemical reaction.
\end{abstract}

Keywords: cassiterite; calcite; flotation separation; depressant

\section{Introduction}

As one of the most important strategic metal resources, tin is widely used in the military, information and communication, mechanical materials, and other fields because of its excellent physical and chemical properties [1-3]. As the main source of tin, tin-bearing minerals include stokesite $\left(\mathrm{CaSnSi}_{3} \mathrm{O}_{9} \cdot 2 \mathrm{H}_{2} \mathrm{O}\right)$, cassiterite $\left(\mathrm{SnO}_{2}\right)$, stannite $\left(\mathrm{Cu}_{2} \mathrm{FeSnS}_{4}\right)$, nordenskioldine $\left(\mathrm{CaSnB}_{2} \mathrm{O}_{6}\right)$, and so on [4-6]. Among them, the theoretical tin content in cassiterite is the highest, reaching 78.77\% [7]. Cassiterite is an important tin oxide mineral, which is a raw material for extracting tin and making tin alloys [8-10]. The beneficiation process of cassiterite ore mainly includes gravity separation and flotation, in which flotation is considered to be the most effective way to achieve efficient enrichment of cassiterite [2,11]. Therefore, the research on the flotation separation of cassiterite and associated gangue minerals, such as quartz, calcite, fluorite has attracted many researchers' interest [12-14].

For a successful flotation process, the reagent system is of incomparable importance. At present, the research of cassiterite flotation is mainly focused on exploring the performance and mechanism of new collectors, regulators, and inhibitors [15-17]. For example, Qin et al. confirmed that the chemical adsorption of salicylhydroxamic acid (SHA) on the cassiterite surface is the main reason for the superb flotation performance [18]. Chen et al. found that the floatability of cassiterite with the new frother $\alpha$-terpineol (AT) was nearly 
$10 \%$ higher than the traditional frother methyl isobutyl carbinol (MIBC) with using SHA as the collector [19]. Wang et al. applied a new kind of depressant, disodium salt of adenosine 5 -triphosphate ( $\left.\mathrm{Na}_{2} \mathrm{ATP}\right)$, to enhance the flotation separation of cassiterite and fluorite [20]. There is no doubt that the development and application of new reagents is a good choice to improve the flotation recovery of cassiterite. However, with the continuous exploitation of cassiterite resources, the high-quality cassiterite resources are gradually exhausted, and cassiterite resources tend to be fine, poor, and miscellaneous [21]. It has been gradually realized that the development of a high-performance reagent alone has limited effect on improving the recovery and grade of cassiterite, while the combination of reagents has greater advantages. For example, Cao et al. confirmed that in the presence of $\mathrm{Zn}^{2+}$ and benzohydroxamic acid (BHA), a new type of chelate ring (-Sn-O-Zn-BHA) formed on the cassiterite surface and resulted in the increase of cassiterite flotation recovery [22]. Gong et al. revealed that the collector styrene phosphonic acid (SPA) had a stronger affinity with $\mathrm{Cu}$ (II) than with fluorite surface, and the presence of $\mathrm{Cu}$ (II) enhanced the adsorption of SPA on cassiterite surface [3]. At present, these combined reagents are mainly used to improve the recovery rate of cassiterite. In fact, with the increase of gangue components in cassiterite ore, the effective inhibition of gangue minerals has gradually become the key to improve the grade of cassiterite concentrate [23,24]. However, there is little research on the combined depressants for the gangue associated with cassiterite flotation.

In this study, AlSS, an efficient recipe of depressants, was adopted for the flotation separation of cassiterite and calcite, that is, the combination of $\mathrm{Al}_{2}\left(\mathrm{SO}_{4}\right)_{3}$ and $\mathrm{Na}_{2} \mathrm{O} \cdot \mathrm{nSiO}_{2}$. The inhibition effect of AlSS for cassiterite and calcite in the micro-flotation experiments and artificial experiments was investigated. The underlying flotation separation mechanism was explored by zeta potential measurement, adsorption measurement, contact angle measurement, and XPS measurement. This study has guiding significance for the cassiterite flotation process, and also has reference significance for other mineral flotation separation processes.

\section{Experimental}

\subsection{Materials and Reagents}

Pure minerals of cassiterite and calcite used in the experiments were obtained from Yunnan province, China. After a series of crushing (Jaw crusher), dry grinding (Ceramic ball mill), and screening (Standard sieve), minerals with the particle size of $0.037 \mathrm{~mm}$ to $0.074 \mathrm{~mm}$ were used for flotation experiments. According to the X-ray diffraction of cassiterite (a) and calcite (b) shown in Figure 1, the samples are of high purity. The samples are high-grade cassiterite and calcite with a purity greater than $99 \%$.
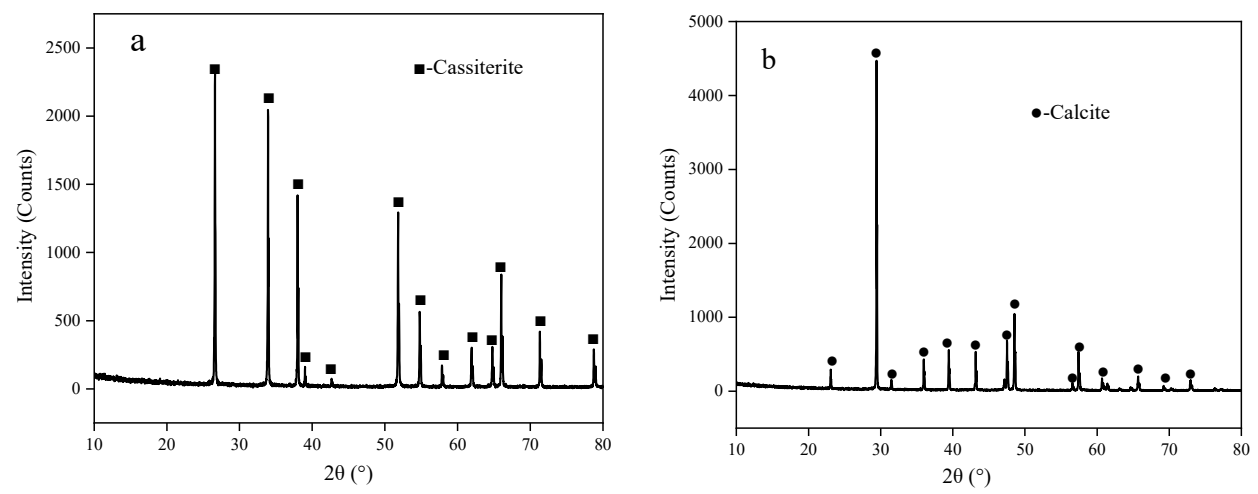

Figure 1. XRD patterns of (a) cassiterite and (b) calcite.

$\mathrm{NaOL}, \mathrm{Na}_{2} \mathrm{SiO}_{3} \cdot 4 \mathrm{H}_{2} \mathrm{O}$ and $\mathrm{Al}_{2}\left(\mathrm{SO}_{4}\right)_{3}$ used in the experiments are of analytical grade. Sodium hydroxide $(\mathrm{NaOH})$ and hydrogen chloride $(\mathrm{HCl})$ solutions were used to adjust the $\mathrm{pH}$ of the slurry. Ultrapure water was used in all the experimental procedures. The complex depressant of AlSS is prepared in advance. If there are no special instructions, AlSS is 
prepared by mixing $\mathrm{Al}_{2}\left(\mathrm{SO}_{4}\right)_{3}$ and $\mathrm{Na}_{2} \mathrm{SiO}_{3} \cdot 4 \mathrm{H}_{2} \mathrm{O}$ in a mass ratio of 1:2. For example, if the concentration of the depressant AlSS is $60 \mathrm{mg} / \mathrm{L}$, then the concentration of $\mathrm{Al}_{2}\left(\mathrm{SO}_{4}\right)_{3}$ is $20 \mathrm{mg} / \mathrm{L}$, and the concentration of $\mathrm{Na}_{2} \mathrm{SiO}_{3} \cdot 4 \mathrm{H}_{2} \mathrm{O}$ is $40 \mathrm{mg} / \mathrm{L}$.

\subsection{Flotation Tests}

Flotation tests consists of single minerals experiments and artificial mixed minerals experiments. Flotation experiments were carried out in XFG flotation machine at a spindle speed of $1200 \mathrm{rpm}$. For each single mineral flotation experiment, $2 \mathrm{~g}$ of pure mineral and $35 \mathrm{~mL}$ of ultrapure water was added to the flotation cell with a capacity of $40 \mathrm{~mL}$. For artificially mixed minerals flotation experiments, $2 \mathrm{~g}$ of the mixed mineral consisted of $1 \mathrm{~g}$ cassiterite and $1 \mathrm{~g}$ of calcite. The flotation experiments were carried out according to the flowsheet shown in Figure 2. After artificial scraping, filtering, drying and weighing, the concentrates and tailings were collected for recovery and grade measurements. The grades of concentrate and tailings of artificial mixed ore are measured by chemical titration analysis. Each experiment was repeated three times. The average was the final result, and the error bar was the standard deviation.

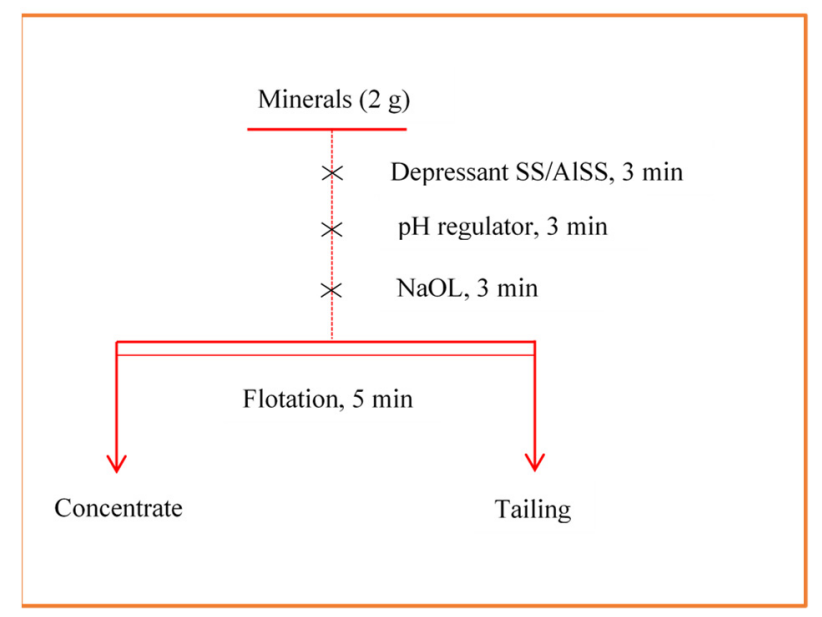

Figure 2. Flowsheet of micro-flotation experiment.

\subsection{Zeta Potential Measurements}

The zeta potential measurements were carried out in a Malvern Zetasizer Nano ZS90 (Malvern, London, UK) equipped with a rectangular electrophoresis cell. The samples used for zeta potential measurement were specially ground to less than $0.02 \mathrm{~mm}$. Before measurement, $30 \mathrm{mg}$ of the single mineral powder was added to $40 \mathrm{~mL}$ of aqueous $\mathrm{KCl}$ $(0.01 \mathrm{~mol} / \mathrm{L})$ solution and conditioned by magnetic stirring, during which reagents were added to the pulp. The concentrations of the reagents added in the zeta potential measurements were consistent with that in the flotation test. After standing for $20 \mathrm{~min}$, the upper clear supernatant was used for zeta potential measurement. The measurement temperature was maintained at $25^{\circ} \mathrm{C}$ and the final result is the average of the three experiments. The average was the final result, and the error bar was the standard deviation.

\subsection{Contact Angle Measurements}

Contact angle measurements were implemented with a JY-82C contact angle meter. The samples used for contact angle measurement were specially treated. Prior to any comminution processes, mineral sample blocks were picked and cut into rectangular parallelepipeds, which are then fixed with resin and finally polished with a polishing machine. Before each sample is tested for contact angle, the surface is polished from coarse to fine until smooth. The mineral surface is polished one after another on the grinder with polishing paper with roughness of 50, 100, 200, 400, 800, 1000, 2000 mesh. In addition, polished surfaces need to be repeatedly washed with deionized water to remove surface 
contaminants. After the surface is naturally air-dried, a drop of deionized water or flotation reagent solution is dropped on the mineral surface and the contact Angle is measured with a contact angle meter. Specially, to ensure the accuracy of the measurement, three contact angle tests were performed on the same sample at different surface locations to obtain the average value.

\subsection{Adsorption Measurements}

The adsorption amount of $\mathrm{NaOL}$ in the experiments was measured with an Elementar TOCII instrument (Elementar Co., Langenselbold, Germany), and the adsorption amount of $\mathrm{Al}^{3+}$ in the experiments was confirmed with an inductively coupled plasma optical emission spectrometry (ICP-OES, Thermo Scientific, Waltham, MA, USA). For each measurement, $2 \mathrm{~g}$ of pure mineral and $35 \mathrm{~mL}$ of deionized water are added to a Plexiglas cell $(40 \mathrm{~mL})$, and flotation reagents are added when the pulp was stirred. After the adsorption is completed, the pulp volume is fixed to $50 \mathrm{~mL}$, then the solid-liquid separation is carried out by centrifugation, and finally, the supernatant is taken for measurement. The adsorption quantity of $\mathrm{NaOL}$ and $\mathrm{Al}^{3+}$ on the mineral surface is calculated as follows:

$$
\begin{gathered}
\Gamma_{1}=\frac{\left(C_{01}-C_{1}\right) \times V}{M} \\
\Gamma_{1}=\frac{\left(C_{02}-C_{1}\right) \times V}{M}
\end{gathered}
$$

$\Gamma_{1}(\mathrm{~mol} / \mathrm{g})$ and $\Gamma_{2}(\mathrm{mg} / \mathrm{g})$ represent the concentration of $\mathrm{NaOL}$ and $\mathrm{Al}^{3+}$ adsorbed on the sample surface, respectively. $C_{01}(\mathrm{~mol} / \mathrm{L})$ and $C_{02}(\mathrm{mg} / \mathrm{L})$ are the initial $\mathrm{NaOL}$ and $\mathrm{Al}^{3+}$ dosage, and $C_{1}$ and $C_{2}$ denote the residual $\mathrm{NaOL}$ and $\mathrm{Al}^{3+}$ dosage in the pulp, respectively. $\mathrm{V}$ and $\mathrm{M}$ are the volumes of the solution and the weight of the minerals, respectively.

\subsection{XPS Measurements}

XPS analyses were performed with an ESCALAB 250Xi energy spectrometer using monochromatic Al K $\alpha$ radiation (Thermo Fisher Scientific Corporation, Waltham, MA, USA). The measurement scan was performed in a single scan from 1350 to $0 \mathrm{eV}$, with a residence time of $8 \mathrm{~s}$, passing energy of $150 \mathrm{eV}$, and a step size of $1 \mathrm{eV}$. All binding energies were calibrated using the characteristic $C 1$ s carbon peak $(\mathrm{C} 1 \mathrm{~s}=284.7 \mathrm{eV})$. The samples used for XPS measurement were prepared in the same way as flotation experiments, except that the concentrate after the final filtration needs to be flushed with deionized water three times.

The chemical states of elements are assigned based on the PHI and NIST XPS databases.

\section{Results and Discussion}

\subsection{Flotation Results}

$\mathrm{NaOL}$ is one of the most commonly used collectors for cassiterite flotation [25]. The flotation recovery of cassiterite and calcite in the presence of $\mathrm{NaOL}$ is presented in Figure $3 \mathrm{a}$. As can be seen in Figure 3a, under different $\mathrm{pH}$, because the occurrence state of NaOL and the dissolution behavior of cassiterite are different, leading to a certain difference in the flotation recovery of cassiterite. However, on the whole, cassiterite shows a good flotation performance in the presence of $\mathrm{NaOL}$, especially when the $\mathrm{pH}$ is 8.45 , the recovery of cassiterite reaches $94.25 \%$. As for calcite, in the whole flotation $\mathrm{pH}$ range, the flotation recoveries of calcite are higher than $80 \%$ indicating the selectivity of $\mathrm{NaOL}$ is poor. When the depressant SS is added, the flotation recoveries of cassiterite and calcite are shown in Figure 3b. As can be seen from Figure 3b the inhibition effect of SS on calcite is stronger than that on cassiterite because the recovery rate of calcite is reduced to about $50 \%$, while the recovery rate of cassiterite is only reduced by about $10 \%$. It is clear that the flotation separation of cassiterite from calcite is still very hard with the depressant SS alone since the flotation recovery of calcite is still very high. 

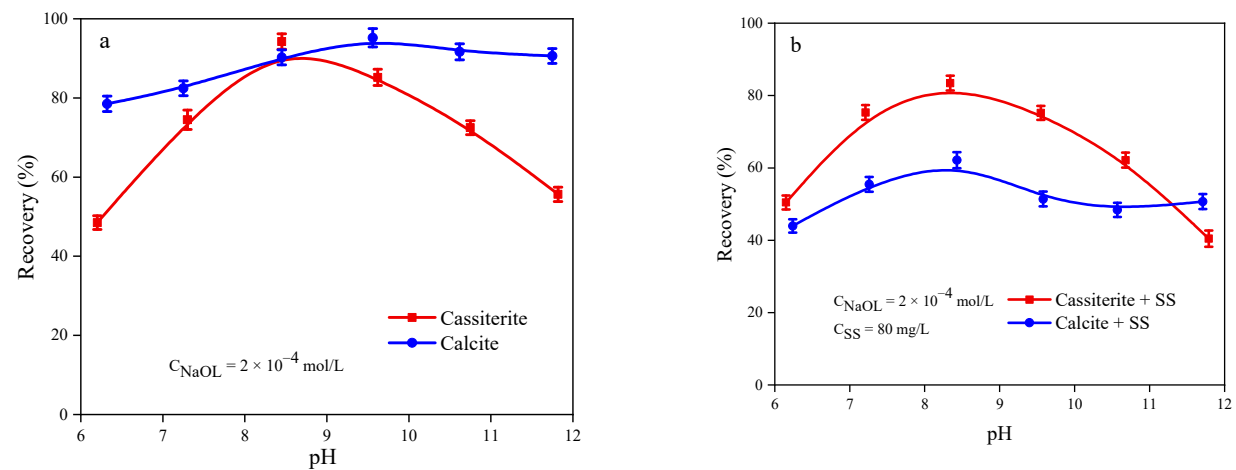

Figure 3. Flotation recovery of cassiterite and calcite in the presence of $\mathrm{NaOL}$ (a) and SS (b).

$\mathrm{Al}_{3}\left(\mathrm{SO}_{4}\right)_{2}$ is a common flotation reagent, which is used as regulator or flocculant. The flotation recovery of cassiterite and calcite in the presence of $\mathrm{Al}^{3+}$ is shown in Figure 4. As shown in Figure 4, with the addition of $\mathrm{Al}^{3+}$, both the flotation recoveries of cassiterite and calcite decrease to a certain extent, and the recovery of calcite decreases more obviously. This may be because the added aluminum ions will combine with the collector sodium oleate to form aluminum oleate, which consumes part of the collector. However, overall, under the action of aluminum ions, the recovery rate of calcite is still very high between $60 \%$ and $80 \%$. It is obvious that the flotation separation of cassiterite and calcite is still not feasible in the presence of $\mathrm{Al}_{3}\left(\mathrm{SO}_{4}\right)_{2}$.

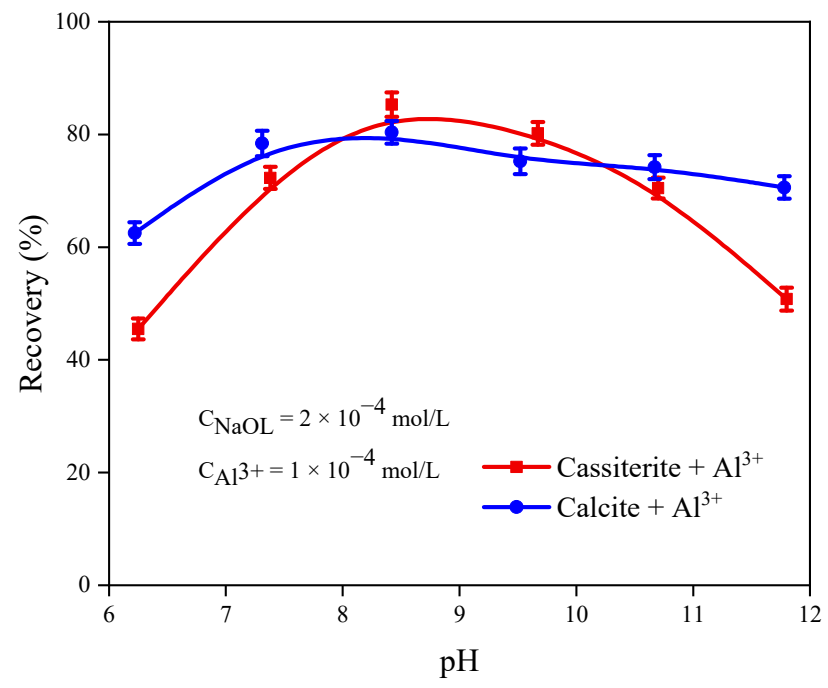

Figure 4. Effect of $\mathrm{Al}_{2}\left(\mathrm{SO}_{4}\right)_{3}$ on the flotation recovery of cassiterite and calcite.

Figure 5 depicts the flotation recoveries of cassiterite and calcite in the presence of the combined depressant AlSS. As can be seen in Figure 5a, the flotation recoveries of cassiterite increase from $56.45 \%$ at the $\mathrm{pH}$ of 6.19 to the maximum of $82.45 \%$ at the $\mathrm{pH}$ of 8.50 and then slowly decreased to a minimum of $45.45 \%$ at the $\mathrm{pH} 11.81$ with the continuous increase of $\mathrm{pH}$. Similar to the recovery of cassiterite without AlSS, hence no real change in cassiterite recovery. For calcite, the flotation recoveries increased slowly from $3.65 \%$ to $16.2 \%$ in the whole investigated $\mathrm{pH}$ range. At the $\mathrm{pH}$ of 8.5 , the influence of AlSS concentration on the flotation recoveries is shown in Figure $5 \mathrm{~b}$. With the increase of AlSS concentration from $0 \mathrm{mg} / \mathrm{L}$ to $100 \mathrm{mg} / \mathrm{L}$, the flotation recoveries of cassiterite decrease slowly from $93.85 \%$ to $80.15 \mathrm{mg} / \mathrm{L}$, while the flotation recoveries of calcite decrease sharply from $90.05 \%$ to $5.75 \%$. There is no doubt that AlSS has good selectivity for the flotation recovery of cassiterite and calcite. 

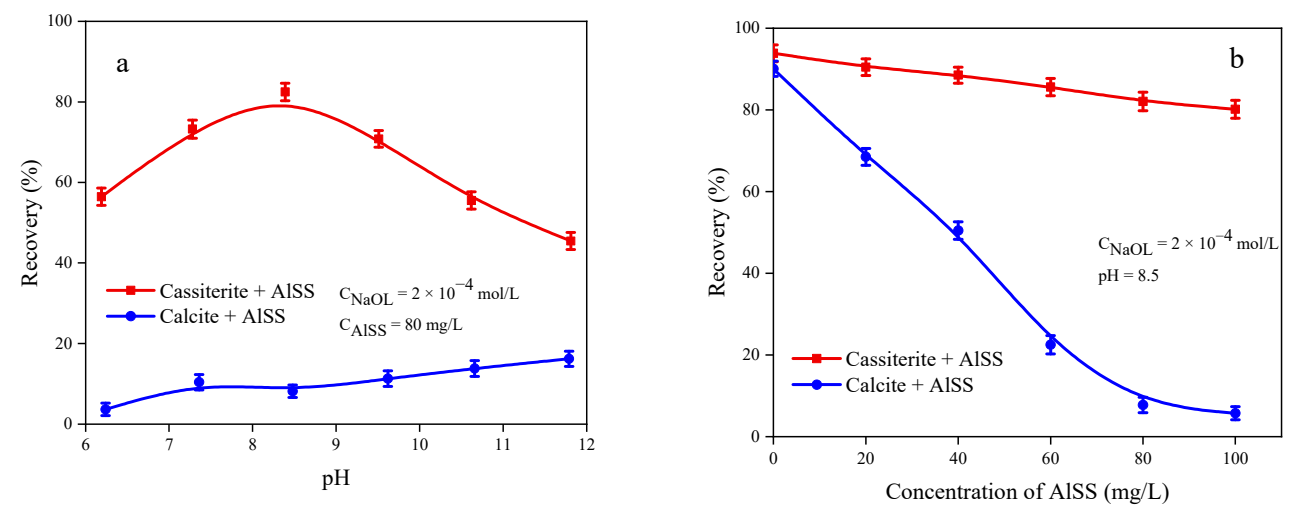

Figure 5. Effect of $\mathrm{pH}(\mathbf{a})$ and concentration $(\mathbf{b})$ of SS on the flotation recovery of cassiterite and calcite.

For the application of mixed reagents, the mixing ratio of different components has a significant impact on the performance of combination treatment [26]. Figure 6 demonstrates the influence of the mass ratio between $\mathrm{Al}^{3+}$ and SS on the flotation recovery of cassiterite and calcite. As shown in Figure 6, with the increase of the mass ratio of $\mathrm{Al}_{2}\left(\mathrm{SO}_{4}\right)_{3}$ to SS, the flotation recovery of cassiterite fluctuates slightly, while the flotation recovery of calcite first decrease first and then increases. With the mass ratio of $\mathrm{Al}_{2}\left(\mathrm{SO}_{4}\right)_{3}: \mathrm{SS}=2: 1$, the flotation recovery difference between cassiterite and calcite is the largest, reaching $74.3 \%$, and the flotation recovery of cassiterite is the highest among the investigated mass ratios. This is also the reason why the mass ratio of $\mathrm{Al}^{3+}$ to SS is chosen as 2:1 during the research.

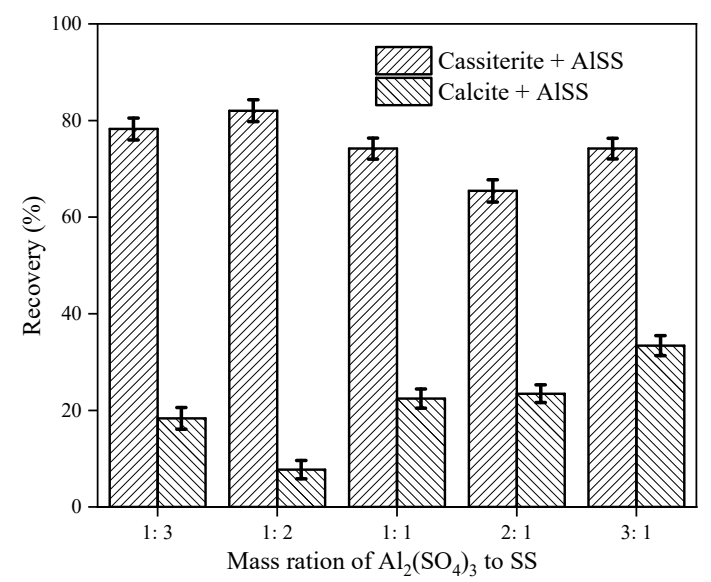

Figure 6. Effect of the mass ratio between $\mathrm{Al}_{2}\left(\mathrm{SO}_{4}\right)_{3}$ to $\mathrm{SS}$ to the flotation recovery of cassiterite and calcite.

Because the micro-flotation results proves that the mixed depressant AlSS shows good selectivity for the flotation separation of cassiterite and calcite, artificially mixed minerals flotation experiments were carried out to further confirm the performance of AISS. Table 1 exhibits the flotation results of mixed minerals. As can be seen from Table 2, in the presence of the collector $\mathrm{NaOL}$ alone, the grade and recovery of $\mathrm{SnO}_{2}$ are $46.65 \%$ and $82.27 \%$, respectively. With the addition of the depressant SS, the flotation recovery of $\mathrm{SnO}_{2}$ is almost unchanged, reaching $82.07 \%$, while the grade of $\mathrm{SnO}_{2}$ increases slightly, reaching $10.71 \%$. In the presence of $\mathrm{NaOL}$ and AlSS, though the flotation recovery of $\mathrm{SnO}_{2}$ decreases slightly to $77.38 \%$, the grade of $\mathrm{SnO}_{2}$ increased sharply to $82.34 \%$. Obviously, the depressant AlSS also demonstrates super selectivity for the flotation separation of cassiterite from calcite during mixed minerals flotation. 
Table 1. Flotation results of mixed minerals $(\mathrm{pH}=8.5, \mathrm{NaOL}=0.2 \mathrm{mM}, \mathrm{AlSS}=80 \mathrm{mg} / \mathrm{L})$.

\begin{tabular}{ccccc}
\hline Reagents & Products & Yield (\%) & $\mathbf{S n O}_{\mathbf{2}}$ Grade (\%) & $\mathbf{S n O}_{\mathbf{2}}$ Recovery (\%) \\
\hline \multirow{3}{*}{ NaOL (0.2 $\mathbf{~ M M )}$} & Concentrate & 85.57 & 46.65 & 82.27 \\
& Tailing & 14.43 & 59.61 & 17.73 \\
& Feed & 100 & 48.52 & 100 \\
\hline \multirow{2}{*}{ NaOL (0.2 $\mathbf{~ M M ) ~}$} & Concentrate & 69.52 & 57.34 & 82.07 \\
SS (80 $\mathbf{~ g / L ) ~}$ & Tailing & 30.48 & 28.57 & 17.93 \\
& Feed & 100 & 48.57 & 100 \\
\hline \multirow{2}{*}{ NaOL (0.2 $\mathbf{~ M )}$} & Concentrate & 45.56 & 82.34 & 77.38 \\
AlSS (80 $\mathbf{~ g / L ) ~}$ & Tailing & 54.43 & 20.15 & 22.62 \\
& Feed & 100 & 48.49 & 100 \\
\hline
\end{tabular}

Table 2. Atomic concentrations and the shifts of elements on the calcite surface.

\begin{tabular}{ccccc}
\hline & \multirow{2}{*}{ Elements } & \multicolumn{2}{c}{ Conditions } & \multirow{2}{*}{ Shift } \\
\cline { 3 - 4 } & & Calcite & Calcite + AlSS & \\
\hline & Ca 2p & 13.92 & 7.84 & -6.08 \\
Concentration (\%) & O 1S & 41.77 & 46.68 & 4.91 \\
& C 1S & 44.31 & 34.58 & -9.73 \\
& Si 2p & - & 6.28 & +6.28 \\
& Al 2p & - & 4.64 & +4.64 \\
\hline
\end{tabular}

\subsection{Zeta Potential Measurements Results}

The adsorption of reagent molecules on the surface of the mineral will lead to the change of minerals surface electrical properties, which can be measured by zeta potential experiments $[27,28]$. Thus, zeta potential measurements were carried out to uncover the possible interaction mechanism between flotation reagents and minerals.

Figure 7 is the species distribution diagram of $\mathrm{Al}^{3+}$ (a) and the distribution coefficient of water glass (b). As can be seen in Figure 6, with the increase of $\mathrm{pH}$, the main forms of $\mathrm{Al}^{3+}$ in the solution are $\mathrm{Al}^{3+}, \mathrm{Al}(\mathrm{OH})^{2+}, \mathrm{Al}(\mathrm{OH})_{2}{ }^{+}, \mathrm{Al}(\mathrm{OH})_{3}$, and $\mathrm{Al}(\mathrm{OH})_{4}{ }^{-}$, while the main forms of water glass in the solution are $\mathrm{Si}(\mathrm{OH})_{4}, \mathrm{SiO}(\mathrm{OH})_{3}{ }^{-}$, and $\mathrm{SiO}_{2}(\mathrm{OH})_{2}{ }^{2-}$. When $\mathrm{AlSS}$ is added to the pulp, there are two possible ways for the colloidal particles to adsorb on the mineral surface. The first possibility is that the positively charged $\mathrm{Al}_{\mathrm{m}}(\mathrm{OH})_{\mathrm{n}}{ }^{3 \mathrm{~m}-\mathrm{n}}$ colloidal particles first adsorbes on the mineral surface, creating active sites for the adsorption of the negatively charged $\mathrm{SiOm}(\mathrm{OH}) n^{4-2 m-n}$ colloidal particles. The second possibility is that the positively charged $\mathrm{Al}_{\mathrm{m}}(\mathrm{OH})_{\mathrm{n}}{ }^{3 \mathrm{~m}-\mathrm{n}}$ colloidal particles and the negatively charged $\mathrm{SiO}_{\mathrm{m}}(\mathrm{OH})_{\mathrm{n}}{ }^{4-2 \mathrm{~m}-\mathrm{n}}$ colloidal particles will form negatively charged mixed colloidal particles, which can adsorb on the surface of the mineral. Because the AlSS is pre-configured, the latter explanation is more applicable to this system.
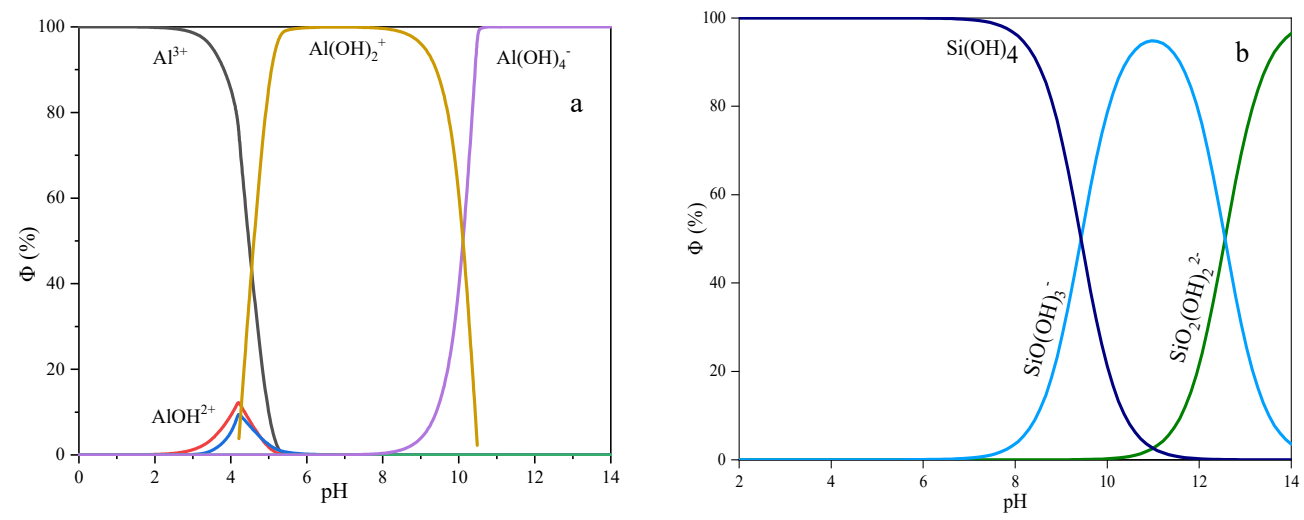

Figure 7. The species distribution diagram of $\mathrm{Al}^{3+}(\mathbf{a})$ and the distribution coefficient of water glass (b) as a function of $\mathrm{pH}$. 
Figure 8 depicts the effect of $\mathrm{pH}$ on the zeta potential of cassiterite and calcite in different systems. As shown in Figure 8a, compared with the zeta potential of cassiterite in the pure water, the addition of AlSS leads to a negligible negative shift of cassiterite among the investigated $\mathrm{pH}$ range (less than $5 \mathrm{mV}$ ). The phenomenon can be explained by the fact that the negatively charged cassiterite surface is difficult to absorb the negatively charged AlSS colloidal particle through electrostatic attraction. In comparison, with the addition of AlSS, the zeta potential of calcite decreases sharply among the investigated $\mathrm{pH}$ range, which may be closely related to the positive surface potential of calcite (Figure $8 b$ ). In the presence of AlSS and NaOL, the zeta potential of cassiterite decreases significantly (more than $20 \mathrm{mV}$ ) and, within the studied $\mathrm{pH}$ range, the decrease is less at both ends and larger in the middle. Because NaOL is an anionic collector, the change of cassiterite surface potential proves that a considerable amount of $\mathrm{NaOL}$ is adsorbed on the cassiterite surface. As for calcite, the zeta potential of calcite only decreases by about $3 \mathrm{mV}$ compared with that of AlSS, which indicates that only a small amount of NaOL is adsorbed on the calcite surface.
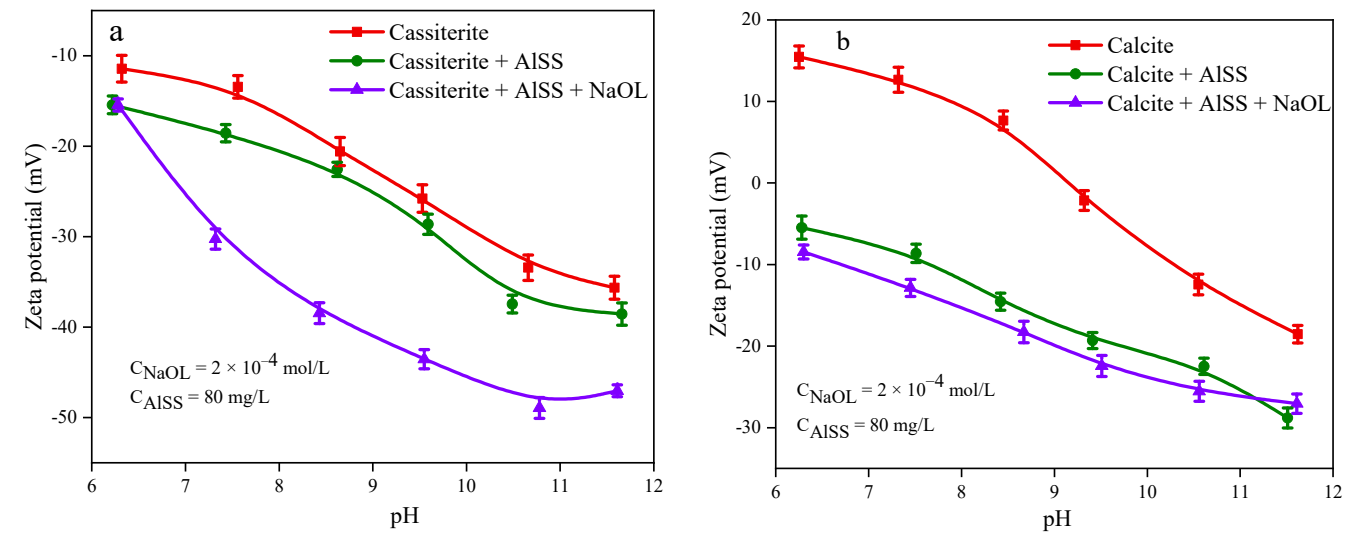

Figure 8. Effect of $\mathrm{pH}$ on the zeta potential of cassiterite (a) and calcite (b) in different systems.

\subsection{Adsorption Test Results}

The adsorption of flotation reagents on the mineral surface is the premise of their effectiveness. Thus, the adsorption measurement is considered an effective method to judge the performance of flotation reagents for different minerals [22].

Figure 9 demonstrates the amount of collector NaOL adsorbed on the cassiterite and calcite surface as a function of the depressant concentration. As shown in Figure 9a, without the addition of depressants, the amount of $\mathrm{NaOL}$ adsorbed on the cassiterite and calcite surface are $3.26 \times 10^{-6} \mathrm{~mol} / \mathrm{g}$ and $3.48 \times 10^{-6} \mathrm{~mol} / \mathrm{g}$, respectively. With the increase of the concentration of the depressant SS, the adsorption of NaOL on the cassiterite surface only decreases slightly, which indicating that the depressant SS has little effect on cassiterite flotation. However, the adsorption of $\mathrm{NaOL}$ on the calcite surface decreases gradually to $1.96 \times 10^{-6} \mathrm{~mol} / \mathrm{g}$ when the concentration of SS reaches $100 \mathrm{mg} / \mathrm{L}$. This result is also consistent with the fact that the recovery of cassiterite is only reduced by nearly $5 \%$, while that of calcite is reduced by more than $30 \%$ under the action of SS. When the depressant is changed to AlSS, as shown in Figure 9b, the adsorption of NaOL on the cassiterite surface still shows an inapparent change with the increase of AISS concentration. However, the amount of NaOL adsorbed on the calcite surface decreases sharply with the increase of AlSS, and the adsorption amount is decreased to $0.62 \times 10^{-6} \mathrm{~mol} / \mathrm{g}$ when the concentration of AlSS reaches $100 \mathrm{mg} / \mathrm{L}$. The change of adsorption amount of collector NaOL on the cassiterite and calcite surface also explains why the recovery of cassiterite does not change much and the recovery of calcite decreases significantly when AlSS is used as a depressant. 

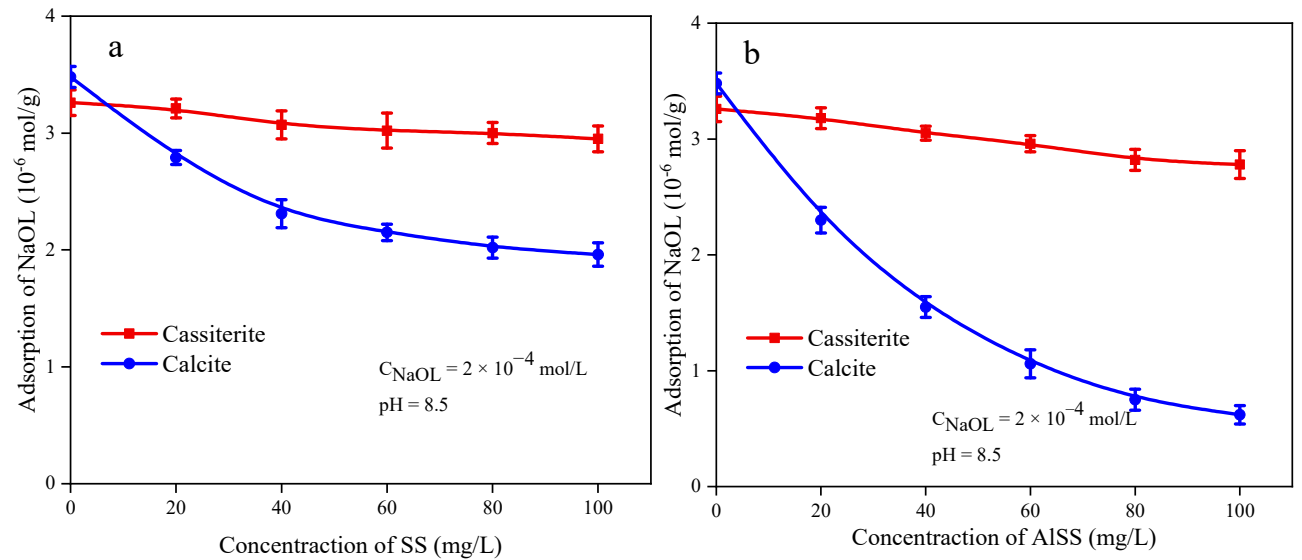

Figure 9. Amount of $\mathrm{NaOL}$ adsorbed on the surface of minerals as a function of the depressant concentration (a) SS and (b) AlSS.

In addition to affecting the adsorption of the collector on the mineral surface, the depressants themselves also adsorb on the mineral surface. It has also been proved that there is competitive adsorption between depressant and collector on the mineral surface [29]. Figure 10 depicts the amount of $\mathrm{Al}^{3+}$ adsorbed on the cassiterite and calcite surface as a function of AlSS concentration. With the increase of AlSS concentration, the amount of $\mathrm{Al}^{3+}$ adsorbed on the cassiterite and calcite surface increases from $0 \mathrm{mg} / \mathrm{g}$ (without the addition of AlSS) to $0.13 \mathrm{mg} / \mathrm{g}$ and $0.52 \mathrm{mg} / \mathrm{g}$, respectively at AlSS concentration of $100 \mathrm{mg} / \mathrm{L}$. The results show that the adsorption of the collectors NaOL and the depressant AlSS on cassiterite and calcite surfaces are in inverse proportion, indicating that there should be competitive adsorption between NaOL and AlSS on the minerals surfaces.

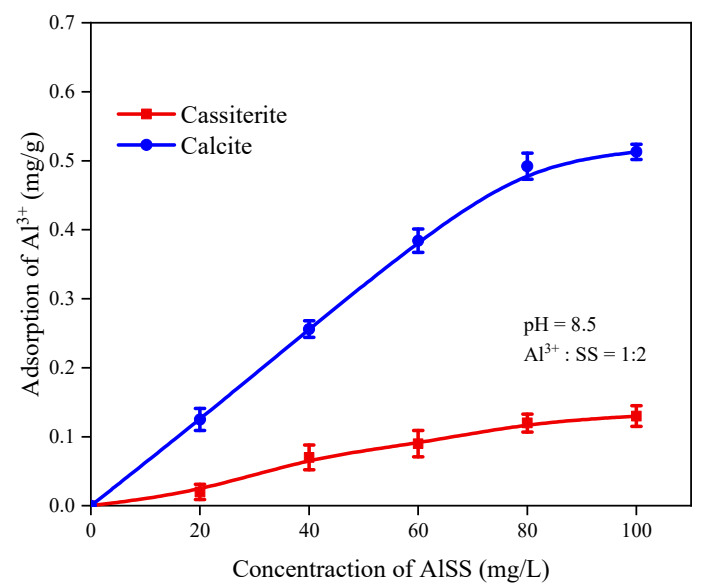

Figure 10. Amount of $\mathrm{Al}^{3+}$ adsorbed on the surface of minerals as a function of AlSS concentration.

\subsection{Contact Angle Measurements}

The flotation process of mineral particles occurs at the solid-liquid-gas three-phase interface. The most direct way to characterize the floatability of mineral particles in a reagent solution is to measure the three-phase contact angle on the mineral surface (Figure 11) and a large three-phase contact angle is usually indicative of good floatability of the mineral in the reagent system [22,30]. Thus, the contact angle measurements are carried out to compare the floatability of cassiterite and calcite in different systems. 


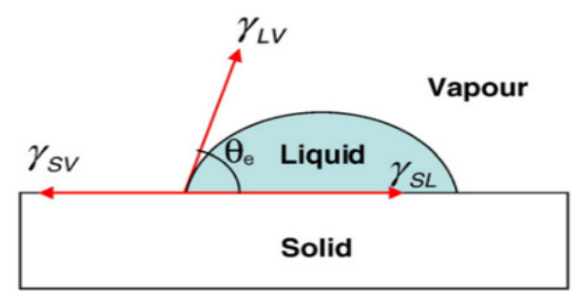

Figure 11. Schematic diagram of contact angle measurement.

Figure 12 demonstrates the contact angles of cassiterite and calcite in the pure water, AlSS, and AlSS + NaOL systems. As shown in Figure 12a,b, in pure water, the contact angle of cassiterite and calcite is $42.35^{\circ}$ and $50.15^{\circ}$, respectively, which indicates that calcite has better natural floatability than cassiterite. In the depressant AISS system, the contact angle of cassiterite and calcite is $35.31^{\circ}$ and $32.78^{\circ}$, respectively. The results indicate that the depressant AISS can decrease the floatability of both cassiterite and calcite. In the system of $\mathrm{NaOL}+\mathrm{AlSS}$, the contact angle of cassiterite and calcite are $85.72^{\circ}$ and $37.26^{\circ}$, respectively, which indicates that cassiterite has good floatability in this system, while calcite has poor floatability. The contact angle results are also consistent with the flotation results.
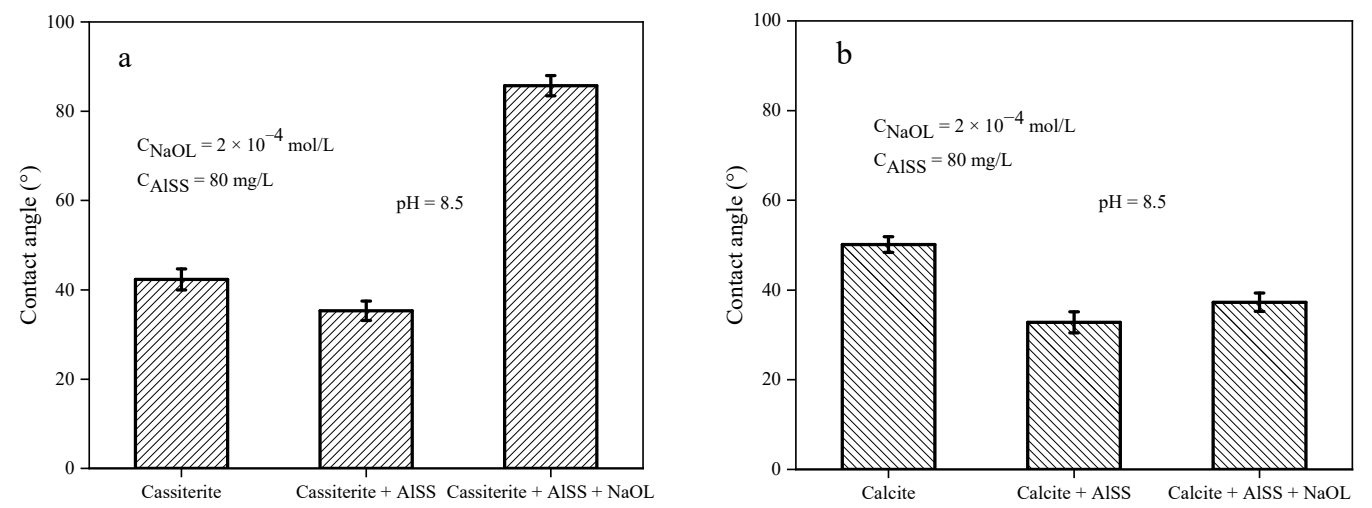

Figure 12. Contact angle of cassiterite (a) and calcite (b) in different systems.

\subsection{XPS Results}

XPS is a sensitive quantitative spectroscopic technique for the analysis of the relative concentrations of various components and the chemical states of metal elements on the surface of the mineral before and after reaction [15,29]. The adsorption of reagents on the surface of the mineral is detected by previous measurements, and XPS analyses are conducted to confirm the interaction mechanism between the minerals and reagents.

Figure 13 demonstrates the survey scan XPS spectra of minerals before and after AlSS treatment. As shown in Figure 13a, except core peaks belonging to $\mathrm{Sn}, \mathrm{O}$, and $\mathrm{C}$, there are no other peaks on the cassiterite surface, indicating the high purity of the sample. After being treated by the depressant AlSS, no new characteristic peak appears on the surface of cassiterite, which indicates that there is no adsorption of AlSS on the surface of cassiterite. The result is somewhat different from the previous adsorption measurement results, which may be related to the different sample preparation methods of the two test methods. In the preparation process of XPS measurement, the sample needs to be washed three times to reduce the residue on the mineral surface. If the adsorption capacity of the reagent on the mineral surface is small or not strong, it will be washed away. For calcite, as shown in Figure 13b, typical peaks, belonging to Al 2p and Si 2p, appeared on the spectrum of calcite after being treated by AlSS, confirming the adsorption of AlSS on the calcite surface. This inference can also be confirmed by the change of element content on the surface of calcite. As shown in Table 2, after being treated by AlSS, the relative atomic concentration of Al 2p and Si 2 p on the calcite surface is up to $4.64 \%$ and $6.28 \%$, respectively, which results in a corresponding decrease in the atomic concentration of $\mathrm{Ca} 2 \mathrm{p}$. 

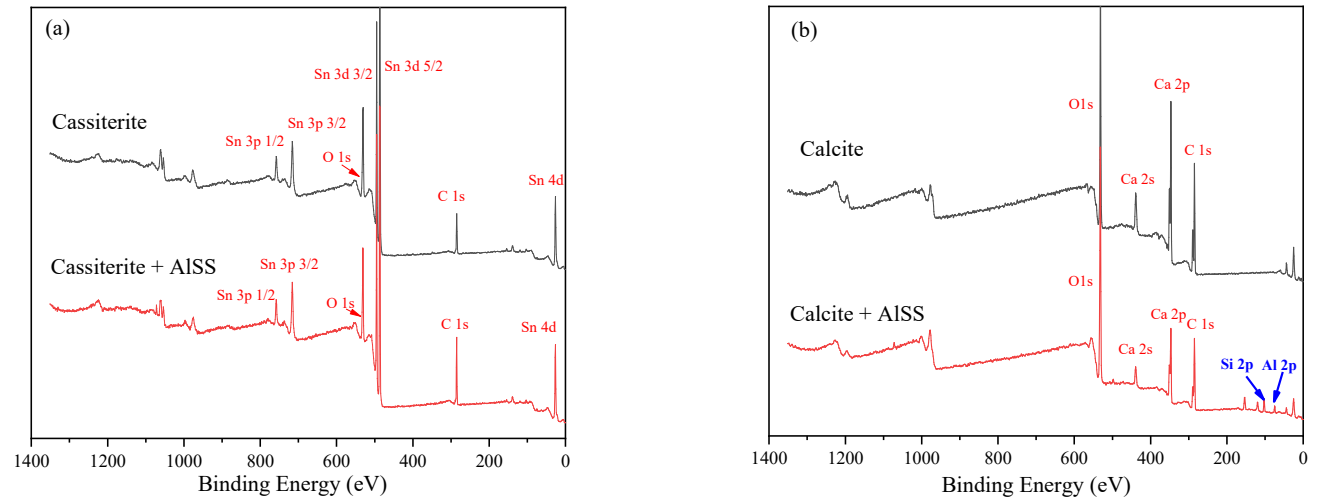

Figure 13. Survey scan XPS spectra of cassiterite (a) and calcite (b) before and after AlSS treatment.

Figure 14 demonstrates the precise scan of $\mathrm{Sn} 3 \mathrm{~d}$ core peaks and Ca $2 \mathrm{p} / 2 \mathrm{~s}$ core peaks on the cassiterite and calcite surface before and after being treated by AlSS. Generally speaking, the change of binding energy in the range of $0.2 \mathrm{eV}$ may be caused by detection error. For a chemical reaction, the change of binding energy of metal elements on the mineral surface will be higher than $0.2 \mathrm{eV}$ [29]. As shown in Figure 13a, in natural conditions, the binding energies of Sn 3d5/2 and Sn 3d3/2 in the spectrum of cassiterite are $486.27 \mathrm{eV}$ and $494.65 \mathrm{eV}$, respectively. After being treated by AlSS, the binding energies of Sn $3 d 5 / 2$ and Sn 3d3/2 are shifted to $486.16 \mathrm{eV}$ and $494.60 \mathrm{eV}$, respectively. Because the peak shifts for $\mathrm{Sn} 3 \mathrm{~d} 5 / 2$ and Sn $3 \mathrm{~d} 3 / 2$ are very small (less than $0.2 \mathrm{eV}$ ), it can be inferred that the chemical environment of cassiterite surface is not changed by the addition of AlSS. For calcite, in the natural condition, the binding energies of $\mathrm{Ca} 2 \mathrm{p}$ and $\mathrm{Ca} 2 \mathrm{~s}$ are $347.05 \mathrm{eV}$ and $350.53 \mathrm{eV}$ and shift to $347.37 \mathrm{eV}$ and $350.75 \mathrm{eV}$, respectively, after being treated with AlSS. Because the change of binding energy of $\mathrm{Ca} 2 \mathrm{p}$ and $\mathrm{Ca} 2 \mathrm{~s}$ on the calcite surface after AlSS treatment is $0.32 \mathrm{eV}$ and $0.22 \mathrm{eV}$, respectively, it can be inferred that the adsorption of AlSS leads to the change of chemical environment on the calcite surface.
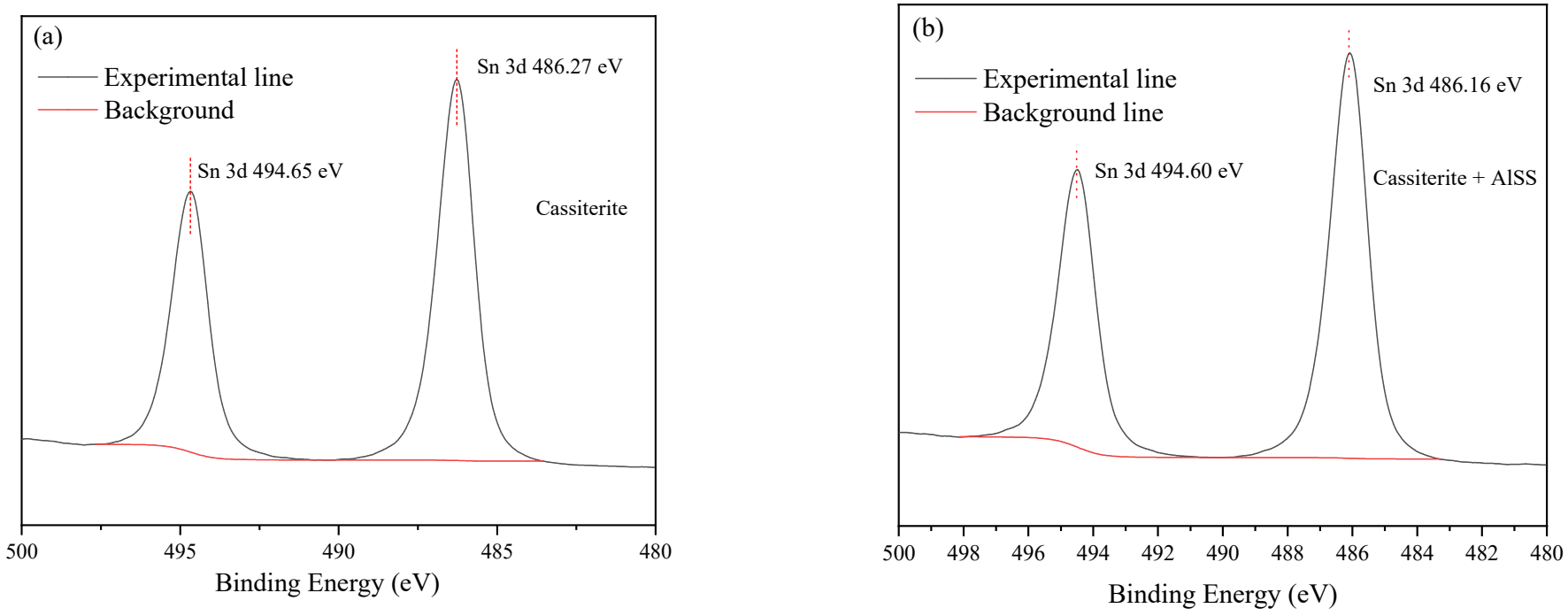

Figure 14. Cont. 

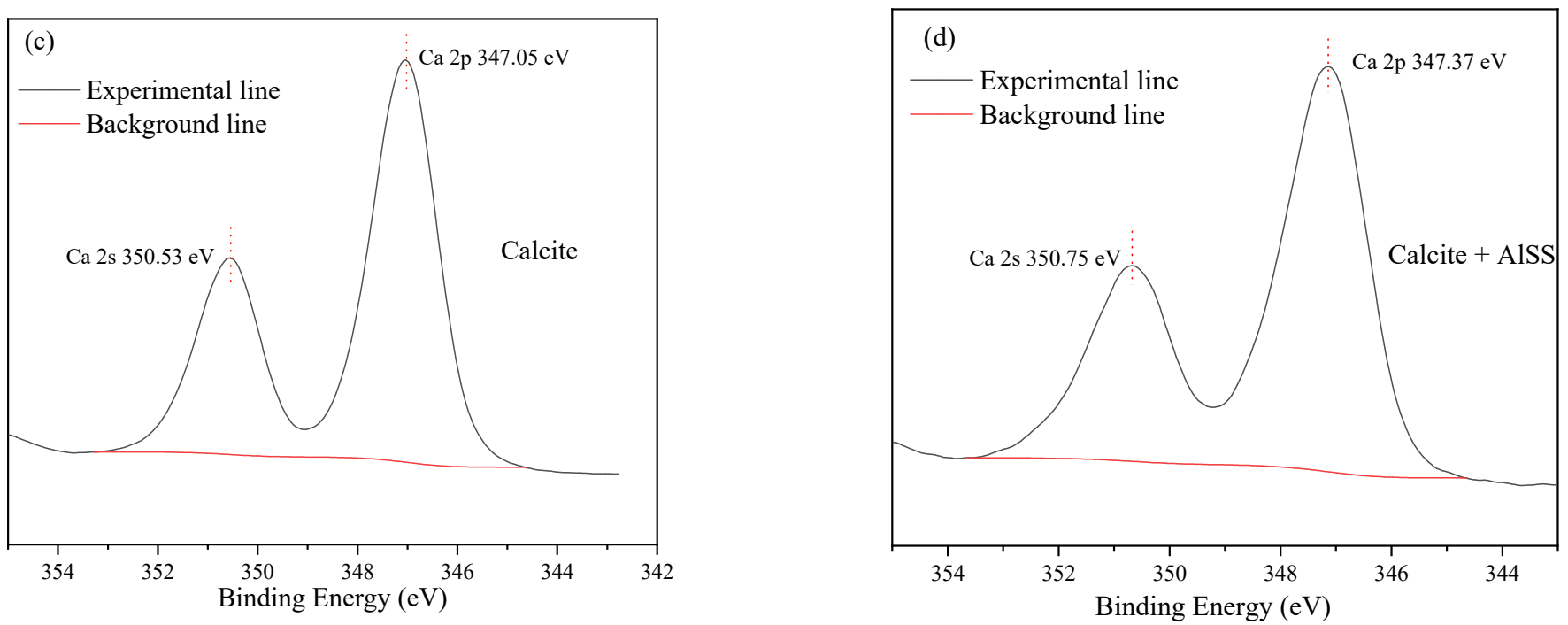

Figure 14. Sn and Ca XPS analysis of cassiterite $(\mathbf{a}, \mathbf{b})$ and calcite $(\mathbf{c}, \mathbf{d})$ before and after AlSS treatment.

To express the whole flotation separation process more clearly, a diagram is drawn and shown in Figure 15. In the flotation separation $\mathrm{pH}$ of 8.5, the surface of cassiterite is negatively charged, while the surface of calcite is positively charged. In the presence of the depressant SS and the collector $\mathrm{NaOL}$, a large amount of $\mathrm{NaOL}$ is adsorbed on both negatively charged cassiterite surface and positively charged calcite surface, so both of them has good floatability. At the same time, the recovery of calcite is lower than that of cassiterite because the SS adsorbed on the surface of calcite is more than that of cassiterite. In the presence of the depressant AlSS and the collector $\mathrm{NaOL}$, a large amount of $\mathrm{NaOL}$ and a small amount of ALSS are still adsorbed on the cassiterite surface, so the cassiterite still has good floatability. However, AlSS can be adsorbed on the surface of calcite through a chemical reaction, which results in competitive adsorption with collector $\mathrm{NaOL}$. As a result, there little $\mathrm{NaOL}$ and a lot of $\mathrm{NaOL}$ adsorbed on surface of the calcite, so the floatability becomes very poor.
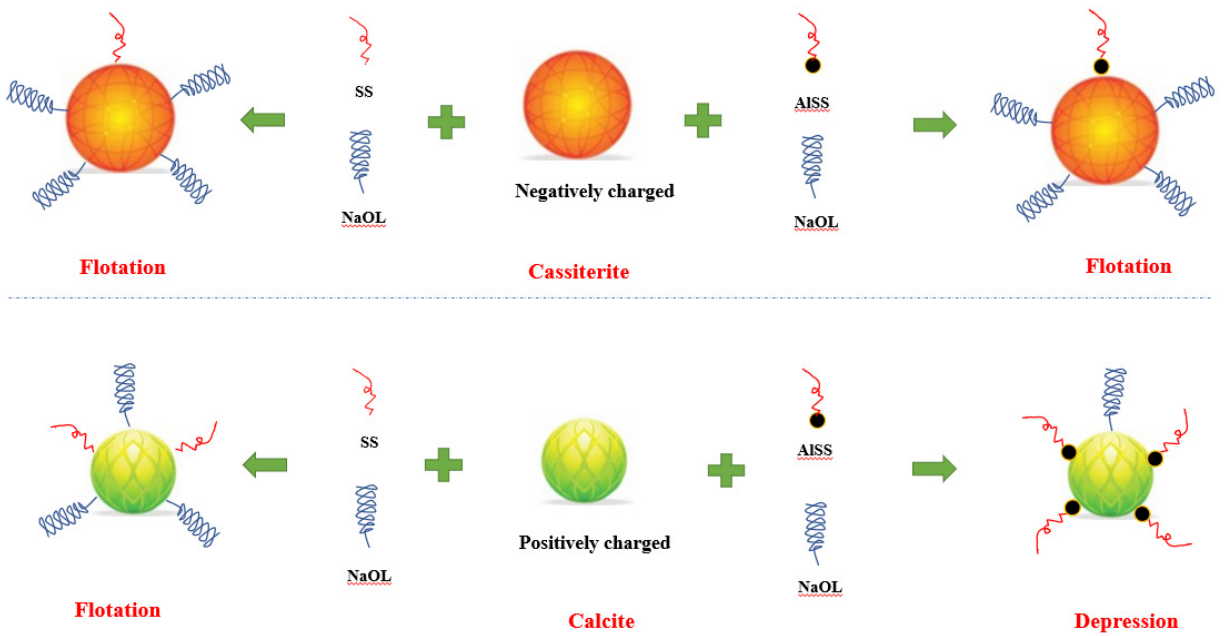

Figure 15. Schematic illustration of the selective flotation process.

\section{Conclusions}

The flotation separation of cassiterite and calcite was investigated in this paper using the collector NaOL and the complex depressant AlSS, and the underlying separation mechanism was revealed by several analysis methods. The main conclusions are as follows. 
(1) Under the optimum conditions of $\mathrm{pH} 8.5, \mathrm{NaOL}$ concentration of $0.2 \mathrm{mM}$, AlSS concentration of $80 \mathrm{mg} / \mathrm{L}$, the flotation separation of cassiterite and calcite can be realized;

(2) In the artificial mixed mineral flotation test, the flotation recovery and grade of $\mathrm{SnO}_{2}$ in the concentrate were $82.34 \%$ and $77.38 \%$, respectively, under the optimum conditions;

(3) Compared with cassiterite, the depressant AlSS is more inclined to adsorb on the surface of calcite, reducing the adsorption amount of collector $\mathrm{NaOL}$ on the surface, and at the same time, reducing its floatability;

(4) The colloidal particles composed of $\mathrm{Al}_{m}(\mathrm{OH})_{n}{ }^{3 m-n}$ and $\mathrm{SiO}_{\mathrm{m}}(\mathrm{OH})_{n}{ }^{4-2 m-n}$ tended to adsorb on the calcite surface through chemical reaction, realizing the goal of selective inhabitation of calcite.

Author Contributions: G.Z.: Methodology, Investigation, Validation, Formal analysis, Writingoriginal draft. D.Z:: Resources, Writing—review \& editing, Supervision, Data curation. All authors have read and agreed to the published version of the manuscript.

Funding: This project was supported by the National Natural Science Foundation of China (51674125, 51604128, 51874150), the Doctoral Scientific Research Foundation of Jiangxi University of Science and Technology (jxxjbs19020), the Jiangxi Provincial Department of Education Science and Technology Research Project (GJJ190486), and the Outstanding Doctoral Dissertation Project Fund of JXUST (YB2016001).

Data Availability Statement: Not applicable.

Acknowledgments: Not applicable.

Conflicts of Interest: The authors declare no conflict of interest.

\section{References}

1. Izard, C.F.; Müller, D.B. Tracking the devil's metal: Historical global and contemporary U.S. tin cycles. Resour. Conserv. Recycl. 2010, 54, 1436-1441. [CrossRef]

2. Angadi, S.I.; Sreenivas, T.; Jeon, H.-S.; Baek, S.-H.; Mishra, B.K. A review of cassiterite beneficiation fundamentals and plant practices. Miner. Eng. 2015, 70, 178-200. [CrossRef]

3. Gong, G.; Wang, P.; Liu, J.; Han, Y.; Zhu, Y. Effect and mechanism of Cu(II) on flotation separation of cassiterite from fluorite. Sep. Purif. Technol. 2020, 238, 116401. [CrossRef]

4. Pavlova, G.G.; Palessky, S.V.; Borisenko, A.S.; Vladimirov, A.G.; Seifert, T.; Phan, L.A. Indium in cassiterite and ores of tin deposits. Ore Geol. Rev. 2015, 66, 99-113. [CrossRef]

5. Yue, T.; Han, H.; Hu, Y.; Wei, Z.; Wang, J.; Wang, L.; Sun, W.; Yang, Y.; Sun, L.; Liu, R. Beneficiation and Purification of Tungsten and Cassiterite Minerals Using Pb-BHA Complexes Flotation and Centrifugal Separation. Minerals 2018, 8, 566. [CrossRef]

6. Gong, G.; Han, Y.; Jie, L.; Zhu, Y.; Shuai, Y. In Situ Investigation of the Adsorption of Styrene Phosphonic Acid on Cassiterite (110) Surface by Molecular Modeling. Minerals 2017, 7, 181. [CrossRef]

7. Chen, Y.; Tong, X.; Feng, D.; Xie, X. Effect of Al (III) Ions on the Separation of Cassiterite and Clinochlore Through Reverse Flotation. Minerals 2018, 8, 347. [CrossRef]

8. Cao, Y.; Tong, X.; Xie, X.; Song, Q.; Zhang, W.; Du, Y.; Zhang, S. Effects of grinding media on the flotation performance of cassiterite. Miner. Eng. 2021, 168, 106919. [CrossRef]

9. Qi, J.; Dong, Y.; Liu, S.; Liu, G. A selective flotation of cassiterite with a dithiocarbamate-hydroxamate molecule and its adsorption mechanism. Appl. Surf. Sci. 2021, 538, 147996. [CrossRef]

10. Jin, S.; Zhang, P.; Ou, L.; Zhang, Y.; Chen, J. Flotation of cassiterite using alkyl hydroxamates with different carbon chain lengths: A theoretical and experimental study. Miner. Eng. 2021, 170, 107025. [CrossRef]

11. Tan, X.; He, F.-Y.; Shang, Y.-B.; Yin, W.-Z. Flotation behavior and adsorption mechanism of (1-hydroxy-2-methyl-2-octenyl) phosphonic acid to cassiterite. Trans. Nonferrous Met. Soc. China 2016, 26, 2469-2478. [CrossRef]

12. Zhang, L.; Khoso, S.A.; Tian, M.; Sun, W. Indium pre-enrichment from a Canadian sulphide ore via flotation technique. Miner. Eng. 2020, 156, 106481. [CrossRef]

13. Gruner, H.; Bilsing, U. Cassiterite flotation using styrene phosphonic acid to produce high-grade concentrates at high recoveries from finely disseminated ores- comparison with other collectors and discussion of effective circuit configurations. Miner. Eng. 1992, 5, 429-434. [CrossRef]

14. Lu, Y.; Wang, S.; Zhong, H. Optimization of conventional hydroxamic acid for cassiterite flotation: Application of structural modification under principle of isomerism. Miner. Eng. 2021, 167, 106901. [CrossRef]

15. Liu, J.; Kong, D.; Xie, R.; Li, Y.; Zhu, Y.; Liu, C. Flotation behavior and mechanism of hydroxycitric acid as a depressant on the flotation separation of cassiterite from calcite. Miner. Eng. 2021, 170, 107046. [CrossRef] 
16. Tian, M.; Liu, R.; Gao, Z.; Chen, P.; Han, H.; Wang, L.; Zhang, C.; Sun, W.; Hu, Y. Activation mechanism of Fe (III) ions in cassiterite flotation with benzohydroxamic acid collector. Miner. Eng. 2018, 119, 31-37. [CrossRef]

17. Sun, Q.; Lu, Y.; Wang, S.; Zhong, H. A novel surfactant 2-(benzylthio)-acetohydroxamic acid: Synthesis, flotation performance and adsorption mechanism to cassiterite, calcite and quartz. Appl. Surf. Sci. 2020, 522, 146509. [CrossRef]

18. Qin, W.; Xu, Y.; Liu, H.; Ren, L.; Yang, C.J.I.; Research, E.C. Flotation and Surface Behavior of Cassiterite with Salicylhydroxamic Acid. Ind. Eng. Chem. Res. 2011, 50, 10778-10783. [CrossRef]

19. Chen, Y.; Li, H.; Feng, D.; Tong, X.; Hu, S.; Yang, F.; Wang, G. A recipe of surfactant for the flotation of fine cassiterite particles. Miner. Eng. 2021, 160, 106658. [CrossRef]

20. Wang, X.; Liu, J.; Zhu, Y.; Li, Y. The application and mechanism of high-efficiency depressant Na2ATP on the selective separation of cassiterite from fluorite by direct flotation. Miner. Eng. 2021, 169, 106963. [CrossRef]

21. Bru, K.; Sousa, R.; Leite, M.M.; Broadbent, C.; Stuart, G.; Pashkevich, D.; Martin, M.; Kern, M.; Parvaz, D.B. Pilot-scale investigation of two Electric Pulse Fragmentation (EPF) approaches for the mineral processing of a low-grade cassiterite schist ore. Miner. Eng. 2020, 150, 106270. [CrossRef]

22. Cao, Y.; Sun, L.; Gao, Z.; Sun, W.; Cao, X.J.M.E. Activation mechanism of zinc ions in cassiterite flotation with benzohydroxamic acid as a collector. 2020,156, 106523. Minerals Eng. 2020, 156, 106523. [CrossRef]

23. Tian, M.; Gao, Z.; Ji, B.; Fan, R.; Liu, R.; Pan, C.; Wei, S.; Hu, Y. Selective Flotation of Cassiterite from Calcite with Salicylhydroxamic Acid Collector and Carboxymethyl Cellulose Depressant. Minerals 2018, 8, 316. [CrossRef]

24. Liu, J.; Gong, G.; Han, Y.; Zhu, Y. New Insights into the Adsorption of Oleate on Cassiterite: A DFT Study. Minerals 2017, 7, 236. [CrossRef]

25. Feng, Q.; Wen, S.; Zhao, W.; Chen, Y. Effect of calcium ions on adsorption of sodium oleate onto cassiterite and quartz surfaces and implications for their flotation separation. Sep. Purif. Technol. 2018, 200, 300-306. [CrossRef]

26. Wu, H.; Tian, J.; Xu, L.; Fang, S.; Zhang, Z.; Chi, R. Flotation and adsorption of a new mixed anionic/cationic collector in the spodumene-feldspar system. Miner. Eng. 2018, 127, 42-47. [CrossRef]

27. Wang, Z.; Wu, H.; Yang, J.; Tang, Z.; Luo, L.; Shu, K.; Xu, Y.; Xu, L. Selective flotation separation of bastnaesite from calcite using xanthan gum as a depressant. Appl. Surf. Sci. 2020, 512, 145714. [CrossRef]

28. Pan, G.; Zhang, G.; Shi, Q.; Chen, W. The Effect of Sodium Alginate on Chlorite and Serpentine in Chalcopyrite Flotation. Minerals 2019, 9, 196. [CrossRef]

29. Wang, C.; Liu, R.; Sun, W.; Jing, N.; Xie, F.; He, Q.Z.D. Selective depressive effect of pectin on sphalerite flotation and its mechanisms of adsorption onto galena and sphalerite surfaces. Miner. Eng. 2021, 170, 106989. [CrossRef]

30. Muganda, S.; Zanin, M.; Grano, S.R. Influence of particle size and contact angle on the flotation of chalcopyrite in a laboratory batch flotation cell. Int. J. Mineral Processing 2011, 98, 150-162. [CrossRef] 